\title{
Features of the Motivation of Russian and Foreign Students Studying at the University
}

\author{
Elena Perchenko ${ }^{1}{ }^{*}$ Tatiana Gudina ${ }^{1}$
}

\author{
${ }^{1}$ Cherepovets State University, Russia \\ *Email:pel.mail@mail.ru
}

\begin{abstract}
The importance of the problem of motivation in training a specialist is dictated by the qualitatively changing conditions of modern society and the action of those new requirements that are imposed on the learning process and the formation of professionally significant competencies. This predetermines the restructuring of education in general and each of its aspects, especially in the training of future specialists aimed at the successful completion of educational activities, the manifestation of professional and creative persistence in solving difficult problems and realizing their potential. Basing on the analysis of scientific sources, we can formulate the purpose of our study, which is to acknowledge the features of the motivational complex of Russian students in comparison with foreign ones studying in universities in our country. Basing on the results, we came to the conclusion that there are still differences in the characteristics of the motivational complex of the selected groups. Russian students are more focused on acquiring professional competencies that will ensure their future success and self-realization in their chosen profession. For foreign students from the near abroad, the most significant is pragmatic motivation with a focus on personal prestige in their ethnic group. The formed optimal motivational complex ensures the individual's achievement of success in the course of constant competition with himself, in the desire to achieve new, higher results in comparison with his previous ones. The process and result of the development of the complex under consideration has a decisive influence on the professional development of students, future specialists.
\end{abstract}

Keywords: Optimal motivational complex of a student, Professional competencies, Social and psychological training.

\section{INTRODUCTION}

The problem of motivation of activity is one of the fundamental ones both in domestic and foreign psychology. It reveals itself especially clearly in educational activity, which, moreover, takes place in the qualitatively changing conditions of modern society and under the influence of those new requirements that are imposed on the learning process and the formation of professionally significant personality traits.

In our research, we rely on two opposite tendencies in the field of motivation, in which we propose to distinguish the motive of "achievement in activity" - the desire for success, and the motive of "avoiding failure" (J. Atkinson [1]). This approach made it possible to identify and characterize a number of the most important characteristics of individuals with productive motivation for activity, which include the desire to solve difficult problems, perseverance, focus on completing the work begun, features of the reaction to failure, etc.

Motivation is the main driving force in human activity, including in the process of forming a future professional. Therefore, the question of incentives and aspirations in the educational and professional activities of students becomes especially important and is dependent on the following circumstances:

- modern society needs people with a high level of general and professional education, who are proactive and entrepreneurial, aimed at solving complex and nonordinary tasks with the ability to think creatively. This predetermines the restructuring of the learning process in general and each of its aspects, especially motivational; 
- a significant part of human life is devoted to obtaining the necessary professional competencies and obtaining certain qualifications in secondary and higher professional educational institutions, as a result of which the motivation for achieving success in learning is one of the central in pedagogy and educational psychology;

- in connection with the stressful changes taking place in the socio-economic life of the country in recent years, the task of preparing future specialists for independent professional and creative activities who realize their potential is one of the conditions for their formation.

For the majority of modern students, educational activities are increasingly becoming formal in nature, and often, the students are more focused not on the assimilation of new knowledge, but on the successful exam pass by any means. In this regard, the study of motivation to acquire knowledge and corresponding competencies, focus on solving complex tasks and the completion of the started activity becomes extremely important.

Within this study, the main point of interest is the problem of studying the educational motivation of students studying in universities. In this regard, we can note the works of the following scientists: V.G. Aseeva [2], N.S. Barebina [3], N.E. Gorskaya [3], V.E. Glyzina [3], NS Barebina [3], G.A. Dumenko [4], V.I. Dolgova [5], L.G. Zhdanova [6], A.K. Medvedeva [7]; foreign authors: P.P. Baard, E.L. Deci, R.M. Ryan [8]; M.S. Hagger, N.L. Chatzisarantis [9], which reveal the structure of motivation for educational activity and its role, as well as the mechanism of the emergence of educational motives.

The study of N.E. Gorskaya, V.E. Glyzyna and N.S. Barebina helped us to reveal different types of educational motivation: progressive, impulsive, expressive, flattened and regressive [3].

G.A. Dumenko notes that the leading motives of learning and independence among students from the chosen specialty are social, professional and scientificcognitive ones, which reflects the level of their professional self-determination [4].

The productivity of student learning at the university is a predictor of achievement motivation dictated by the desire for success and achievement of the goal set (K.A. Heller [10]; R.J. Sternberg [11]; R.L. Helmreich, J.T. Spence, W.E. Beane, G.W. Lucker., K.A.Matthews [12]; D.H. Schunk, A.R. Hanson, P.D. Cox [13]).

So K.A. Heller notes that the criteria for achieving a result are influenced not only by cognitive predictors of giftedness, but also by non-cognitive (for example, motivational) personal factors, as well as the relationship of sociocultural conditions [10]. R. Sternberg writes, "...The reason why motivation is so important is that people within a given environment — for example, a class - usually exhibit a fairly small range of abilities compared to the range of motivation. Thus, motivation becomes a key source of differences in achieving success between individuals living in a given environment" [11]

At the same time, we should note that the study is aimed at investigating the features of the motivational complex of Russian students in comparison with foreign students studying in our country. Any human activity is polymotivated, prompted by a complex of different motives. Internal, educational and cognitive motives and motives of self-education affect the activity of the individual and the desire to learn, as well as on the success of the activity. The optimal motivational complex ensures the desire for achievement and success in the course of a kind of constant competition with oneself, in the desire to achieve new, higher results in comparison with the previous ones.

\section{MATERIALS AND METHODS}

Analysis and generalization of literary sources made it possible to determine the problem of the study, the purpose of which is to acknowledge the features of the motivational complex of Russian and foreign students studying at the university.

To achieve the goal, the following tasks were set:

- to analyze theoretical and empirical research in accordance with the stated goal;

- to identify the features of educational motivation and motivation for the achievements of Russian and foreign students;

- to study the differences in the motivational complex of Russian and foreign students;

- to create recommendations for the development of an optimal motivational complex among Russian and foreign students studying at the university.

As a general hypothesis, we assumed that there are features in the manifestation of the motivational complex of foreign and Russian students.

The empirical study was held in 2019-2020 at the Cherepovets State University of the Vologda Region. 60 first-year students of various specialties took part in it, including 30 Russian and 30 foreign students from the Republic of Tajikistan.

To identify the features of the motivational complex of Russian and foreign students, the following methods were used:

1. Methodology for the diagnosis of educational motivation of students by A.A. Rean and V.A. Yakunin (modified by N.Ts. Badmaev);

2. Methodology "Motivation for studying at the university" (T.I. Ilyin); 
3. "Motivation for success and fear of failure" (MSF), questionnaire by A.A. Rean.

4. Questionnaire "Scales of academic motivation SHAM" (Gordeeva, Sychev, Osin, 2014).

Fisher's angular transformation criterion $\left(\varphi^{*}\right)$ was used for statistical data processing.

According to the logic of the research and conducting an analytical hierarchy of the whole variety of motives, we identified the degree of variability of students' motivation and presented it in two modifications as insufficient and optimal.

The motivational complex of a university student seems to be optimal when the motivator of educational and professional activity is the need to achieve success, which can only be satisfied when bringing the work to a successful completion and receiving a positive feedback on one's activities. Additional motives are substantive ones for acquiring knowledge and mastering a profession, when the desire to learn new things and to understand the studied subject is accompanied by the experience of interest and pleasure in the process of mastering the profession.

An insufficiently formed motivational complex of a university student includes a predominance of external motivation. The motivation to study is caused by the need to follow the requirements dictated by society, avoidance of possible problems, a sense of duty to oneself and other significant people, but not by their internal need to obtain professional competencies.

\section{RESEARCH RESULT}

The first stage of the empirical study was to identify the features of educational motivation and motivation for the achievements of Russian and foreign students. Basing on the obtained data, we can state that first-year students have a fairly high level of manifestation of motivational activity. Cognitive motives, associated with the content of educational activities and the process of its implementation, the student's orientation towards finding and mastering the necessary competencies in the chosen professional field dominate. There are also fairly high indicators on the scale of communicative and social motives associated with the need for communication, which indicates a desire to build new contacts, to take a certain position in relations with others and earn authority. The predominance of the motives of this group indicates an adequate choice of profession and satisfaction with it.

At the second stage of the study, we tested the first particular hypothesis that foreign students studying at a Russian university tend to avoid failure more often, in contrast to Russian students motivated to achieve success in self-development (table 1).

Note: SM - success motivation, AM - avoidance motive, SDM - self-development motivation, IM introjected motivation, EM - external motivation. Bold type indicates statistically significant differences at $\mathrm{p} \leqq$ 0.01 , normal type indicates values at $\mathrm{p} \leqq 0.05$, “_" - the absence of statistically significant differences.

The analysis of this table shows that foreign students, in contrast to Russian ones, are more inclined to avoid failures, they more often think about possible troubles that may follow in case of failure to perform activities. Such students are distinguished by increased anxiety, lack of confidence in their abilities, they think in advance about ways of avoiding, and not about ways to achieve success. Russian students, in turn, are more focused on achieving success, which characterizes them as responsible, proactive and active in achieving the goal young people confident in themselves and their abilities. Russian first-year students are more likely to strive for the highest possible results in their studies, feeling the pleasure of solving difficult problems. Motivation for self-development $(83.3 \%)$, the development of abilities, their potential in the framework of educational activities, also prevails among Russian students. External motivation stands out among foreign students, particularly -introjected motivation (63.3\%), which measures the motivation to study due to a sense of duty to oneself and significant people. Also, at a fairly high level, foreign students have external motivation (73.3\%), which indicates that they are forced to study and follow the requirements dictated by society.

Next, we tested the second private hypothesis, that the most significant thing for foreign students from

Table 1. Differences in motivation for success and fear of failure among Russian and foreign students $(\%)$

\begin{tabular}{|c|c|c|c|c|c|c|c|}
\hline \multirow[b]{2}{*}{ Students } & \multicolumn{7}{|c|}{ Evaluated parameters } \\
\hline & $\begin{array}{l}\text { Sufficiency } \\
\text { of success }\end{array}$ & $\begin{array}{l}\text { Excess } \\
\text { of failure }\end{array}$ & AM & SM & SDM & IM & EM \\
\hline Foreign & 43 & 57 & 87 & 47 & 63 & 63 & 73 \\
\hline Russian & 67 & 33 & 13 & 70 & 83 & 33 & 23 \\
\hline Differences, $\varphi^{*}$ & \multicolumn{2}{|c|}{3.07} & 6.4 & 1.8 & 1.8 & 2.4 & 4.0 \\
\hline
\end{tabular}


neighboring countries is pragmatic motivation with an orientation towards personal prestige in their ethnic group, and for Russian students, the dominant motives are educational and cognitive, the motive of creative selfrealization and the desire to establish social contacts. It is presented in table 2 .

Note: PM - pragmatic motive (getting a diploma), CM communicative motives, PRM - motives of prestige, CRM motives of creative self-realization, EM - educational and cognitive motives, SM - social motives. Bold type denotes statistically significant differences at $\mathrm{p} \leqq 0.01$, normal type denotes values at $\mathrm{p} \ll 0.05$, “ - "- no statistically significant differences.

Data analysis showed that for foreign students the most significant motive in educational activities is prestige (80\%), it is important for them to get a diploma in a Russian university, which ensures the prestige of higher education. Among Russians, the following predominates in motivation for learning: the communicative motive $(86.7 \%)$, characterizing students as sociable people, easily establishing social contacts and educational and cognitive (93.3\%), which indicates their interest in learning and gaining new knowledge.

Thus, based on the obtained data, we can speak about the presence of an optimal motivational complex among Russian first-year students. In first-year students from the near abroad, we ascertain an insufficiently formed motivational complex.

\section{RESULTS}

Motivation is an integral part of the educational process since it promotes learning activities. Every year there are more students with a low level of educational motivation, which affects not only the quality of education, but also various kinds of barriers, a tendency to avoid failures and the need for recognition, which represents a passive form of education. Basing on the findings of the study, we have developed a sociopsychological training "Development of motivation for learning activities among students studying at a university."

The purpose of the training is to create social and psychological conditions for the development of an optimal motivational complex for learning among university students.

The tasks of the training are:

- generation of students' knowledge about the peculiarities of internal motivation;

- elaboration of personal barriers that prevent the development of an optimal motivational complex;

- the formation of an optimal level of motivation for learning activities and achieving success in selfdevelopment.

The maximum size of the training team is 15 people. The recommended working mode of the group is closed, it assumes that participants can be added only during the first 1-2 lessons. The meetings are held 2 times a week for 1.5 hours. The proposed work plan of the training is designed for 10.5 hours ( 7 meetings over 4 weeks).

The main advantage of this training is the creation of a new psychological construct - a mechanism for realizing the importance of intrinsic motivation and barriers that impede its achievement in Russian and foreign students; Reconsideration and development of individual systems of internal motivational constructs by the training participants, role modeling of their own system of constructs in the training procedure and playing a fixed role in life.

\section{CONCLUSION}

Thus, after our research, we can conclude that there are differences in the features of the motivational complex of Russian and foreign students studying at the university, particularly: for foreign students from the near abroad, the most significant is pragmatic motivation with an orientation towards personal prestige in their ethnic group, and for Russian students the dominant motives are educational and cognitive, the motive for creative selfrealization and the desire to establish social contacts. It was also revealed that foreign students studying at a Russian university are more likely to seek to avoid failure, in contrast to Russian students motivated to achieve success and self-development.

Table 2. Differences in educational motivation of Russian and foreign students (\%)

\begin{tabular}{|l|c|c|c|c|c|c|}
\hline \multirow{2}{*}{ Students } & \multicolumn{7}{c|}{ Evaluated parameters } & SM \\
\cline { 2 - 8 } & PM & CM & PRM & CRM & EM & 80 \\
\hline Foreign & 80 & 67 & 80 & 93 & 77 & 87 \\
\hline Russian & 80 & 87 & 27 & 80 & 93 & - \\
\hline Differences, $\varphi^{\star}$ & - & 1.87 & 4.36 & - & 1.87 & - \\
\hline
\end{tabular}


The proposed socio-psychological training will help the development of internal motivation of students by awakening the participants' desire to develop and achieve success, firstly, in educational activities, secondly professional ones, will create an attitude towards an active work process.

Modern society needs highly educated people with well-formed professional competencies and motivation to achieve the set goals. The basis for the successful educational activity of any student is the disposition to overcome difficulties, the ability to achieve recognition in the chosen profession.

\section{REFERENCES}

[1] J.W. Atkinson, D. Birch, The dynamics of action, N.Y.: Wiley, 1970, 380 p.

[2] V.G. Aseev, Motivation of behavior and personality formation, Mysl, 1976, $158 \mathrm{p}$.

[3] N.E. Gorskaya, Features of the formation of motivation for educational activity of university students in the learning process, Bulletin of the Krasnoyarsk State Pedagogical University 2(36) (2016) 129-133.

[4] G.A. Dumenko, Academic motivation as an indicator of professional self-determination of students, Humanities 4 (2006) 53-60, Stavropol: NCFU.

[5] V.I. Dolgova, Motivation of students' professional activity, Chelyabinsk: CJSC Tsitsero, 2011, 100 p.

[6] L.G. Zhdanova, Some features of student learning motivation, Pedagogical and psychological sciences: modern trends, 2012, 16 p. Novosibirsk: "Siberian Association of Consultants".

[7] T.N. Medvedeva, Features of educational motivation among university students, Scientificmethodical electronic journal "Concept" Vol. 36 (2015) 16-20.

[8] P.P. Baard, E.L. Deci, R.M. Ryan, Intrinsic need satisfaction: A motivational basis of performance and well-being in two work settings, Journal of Applied Social Psychology Vol. 34 (2004) 20452068.

[9] M.S. Hagger, N.L. Chatzisarantis, Intrinsic motivation and self-determination in exercise and sport, Cham-paigne, IL: Human Kinetics, 2007, 392 p.

[10] K.A. Heller, Diagnosis and Development of Gifted Children and Adolescents. Basic modern concepts of creativity and giftedness, 1997, pp. 243-264, Molodaya Gvardiya.
[11] R.J. Sternberg, Successful Intelligence. Simon \& Schuster, 1996, p. 251-252.

[12] R.L. Helmreich, J.T. Spence, W.E. Beane, G.W. Lucker, K.A. Matthews, Making it in Academic Psychology: Demographic and Personality Correlates of Attainment, Journal of Personality and Social Psychology Vol. 39 Iss. 5 (1980) 896-908.

[13] D.H. Schunk, A.R. Hanson, P.D. Cox, Peer model attributes and children's achievement behaviors. Journal of Educational Psychology Vol. 79 (1987) 54-61.

[14] N.Ts. Badmaeva, The influence of the motivational factor on the development of mental abilities. Monograph, Ulan-Ude, 2004, pp. 151-154.

[15] E.P. Ilyin, Motivation and motives, St.P., 2002, 512 p.

[16] A.A. Rean, Practical psychodiagnostics of personality, St. Petersburg, 2001, 224 p.

[17] T.O. Gordeeva_1, O.A. Sychev_2, E.N. Osin_3, Questionnaire "Scales of academic motivation", Psychological journal 4(35) (2014) 96-107. 